\title{
Safe and Sustainable Tall Buildings - State of the Art
}

\author{
Mendis, P. $^{1}$
}

\begin{abstract}
Tall buildings are becoming very popular around the world. Asia will have most of the tall buildings in this century. Both safety and sustainability aspects are important in planning and designing these buildings. The design and construction of tall buildings present many challenges for the design team, from engineers, architect through to the builder. Although structural systems could be developed and construction solutions could be found to design and construct very tall buildings in excess of $1 \mathrm{~km}$ (even 1 mile), other aspects such as fire and egress, long-term movements, environmental wind and perception of motion (including damping for dynamic effects), transportation (lifts) issues, sustainability, durability and maintenance will govern and may even restrict the heights. Current practices and important issues related to design of safe and sustainable design of tall buildings are discussed in this paper.
\end{abstract}

Keywords: Safety, sustainability design, tall buildings.

\section{Introduction}

It is very clear that the epicenter for super tall buildings is moving towards Asia (Figure 1, [1]). Tall buildings have become more and more flexible and taller than in the past, owing to the growing use of high-strength concrete or lighter weight materials and advanced construction techniques. The latest developments in the design of tall buildings are the innovations in construction technology, advances in structural systems and improvements in concrete technology (e.g. ultra high strength concrete) [2]. The buildings are also becoming more "mixed-use" type buildings rather than of particular type as shown in Figure 2.

The significance of lateral loading increases with increasing height, in terms of serviceability, strength and stability limit states.

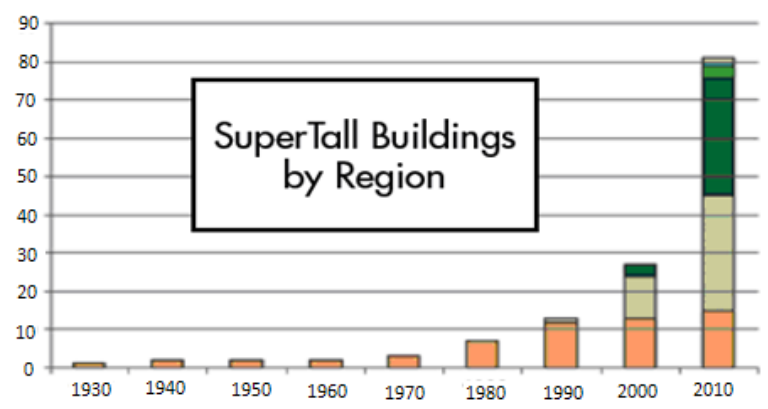

\begin{tabular}{|c|c|c|}
\hline$\square$ North America & South America & Europe \\
\hline Australia & Asia & Middle East+Africa \\
\hline
\end{tabular}

Figure 1. Total Number of Super Tall Buildings in the World by Region

${ }^{1}$ Department of Infrastructure Engineering, The University of Melbourne, Melbourne, AUSTRALIA. Email: pamendis@unimelb.edu.au

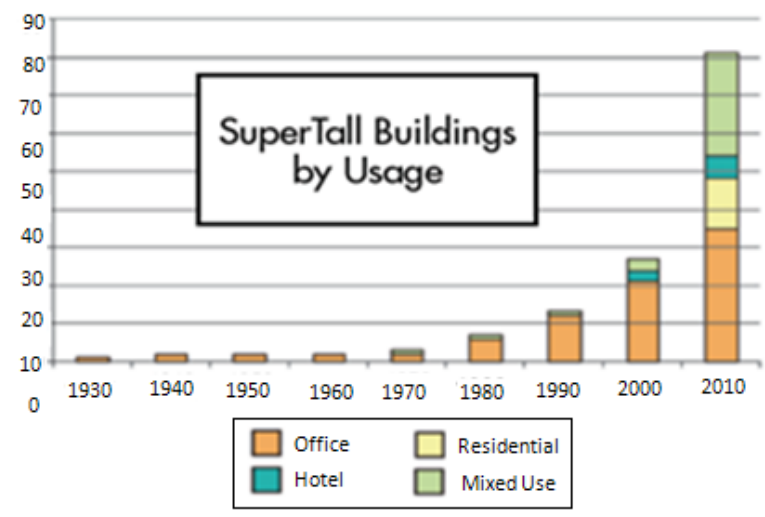

Figure 2. Total Number of Super Tall Buildings in the World by Usage

The design of super tall buildings these days is usually governed by the perception of motion, which is measured by building accelerations. The designing to limit the acceleration is mainly done by the structural engineers, and therefore their role is extremely important in a tall building design team.

Lateral Load resisting structural systems for tall buildings can be categorized as follows:

a. Framed tube (system of rigid frames)

b. Bundled tube (combination of framed tubes)

c. Tube in tube (central and peripheral framed tubes)

d. Diagonalised (trussed tubes, diagrids or braced frames)

e. Core and outrigger (central lateral system linked to the perimeter system through outriggers)

f. Hybrid (combined use of any two or more structural systems).

Core and outrigger systems are essential for super tall buildings. Super tall buildings can be defined as 
buildings more than $400 \mathrm{~m}$ tall. In total, $73 \%$ of the tall buildings built in the 2000s have adopted a core and outrigger system, and approximately 50\% of them are constructed with concrete [3].

\section{Structural Safety of Tall Buildings}

Lateral loading due to either wind and/or seismic loading, generally dominates the structural system of very tall buildings, therefore significantly influencing the overall structural cost.

\section{Wind Design}

Typically for tall building design three basic wind effects need to be considered.

- Environmental wind studies to study the wind effects on the surrounding environment caused by erecting a tall building.

- Wind loads for façade - to assess design wind pressures throughout the surface area of the building to design the cladding system

- Wind loads for structure - to determine the wind loads to design the lateral load resisting structural system of the building to satisfy the various design criteria.

As mentioned earlier, in majority of the super tall buildings designed now, accelerations govern the overall selection and design of the structural system. Acceptability criteria for vibrations in buildings are frequently expressed in terms of acceleration limits for a one or five years return period wind speed, and are based on human tolerance to vibration discomfort in the upper levels of buildings (Figure 3). More details are given by Mendis et al. [4]. Wind response is relatively sensitive to both mass and stiffness, and response accelerations can be reduced by increasing either or both of these parameters. However, this is in conflict with earthquake design optimization where loads are minimized in tall buildings by reducing both the mass and stiffness. Increasing the damping, results in a reduction in both the wind and earthquake responses.

Not only is the wind approaching a building a complex phenomenon, but the flow pattern generated around a building is complicated by the distortion of the mean flow, the flow separation, the vortex formation, and the wake development. Large wind pressure fluctuations due to these effects occur on the surface of a building. As a result, large aerodynamic loads are imposed on the structural system and intense localised fluctuating forces act on the facade of such structures (Figure 4). Under the collective influence of these fluctuating forces, a building vibrates in rectilinear and torsional modes, as illustrated in Figure 4. The amplitude of such oscillations is dependent on the nature of aerodynamic forces and the dynamic characteristics of the building. Unlike low rise buildings, cross-wind forces are significant in tall buildings. Wind tunnel tests are essential to determine these actions in tall buildings.

The numerical simulations using Computational Fluid Dynamic (CFD) techniques to study the wind loads on tall buildings have improved the accuracy and solving time due to advanced developments in numerical techniques as well as the computer hardware. The Large Eddy Simulation (LES) turbulent model has been approved as a suitable model for solving wind engineering problems with a reasonable solving time using current computer power [5].

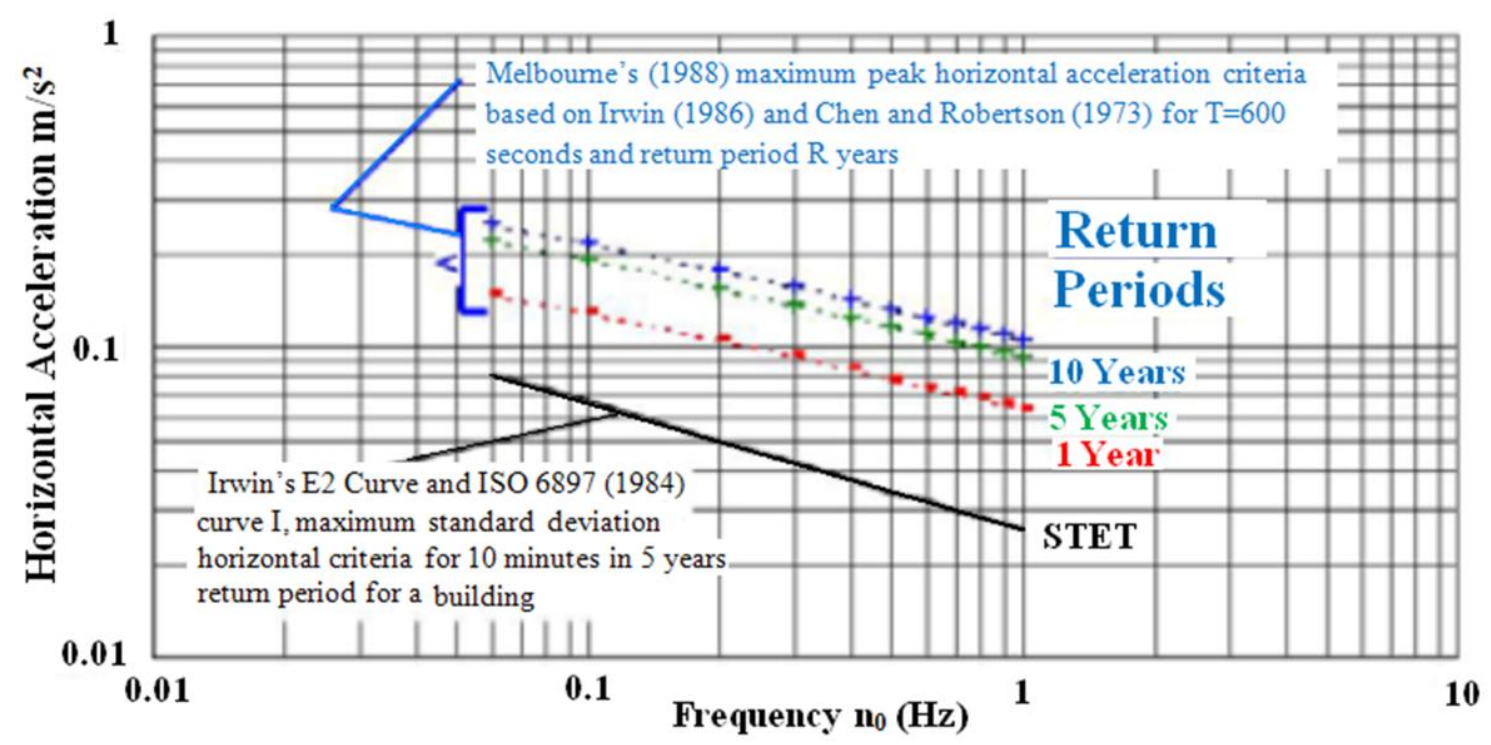

Figure 3. Horizontal Acceleration Criteria for Occupancy Comfort in Buildings 

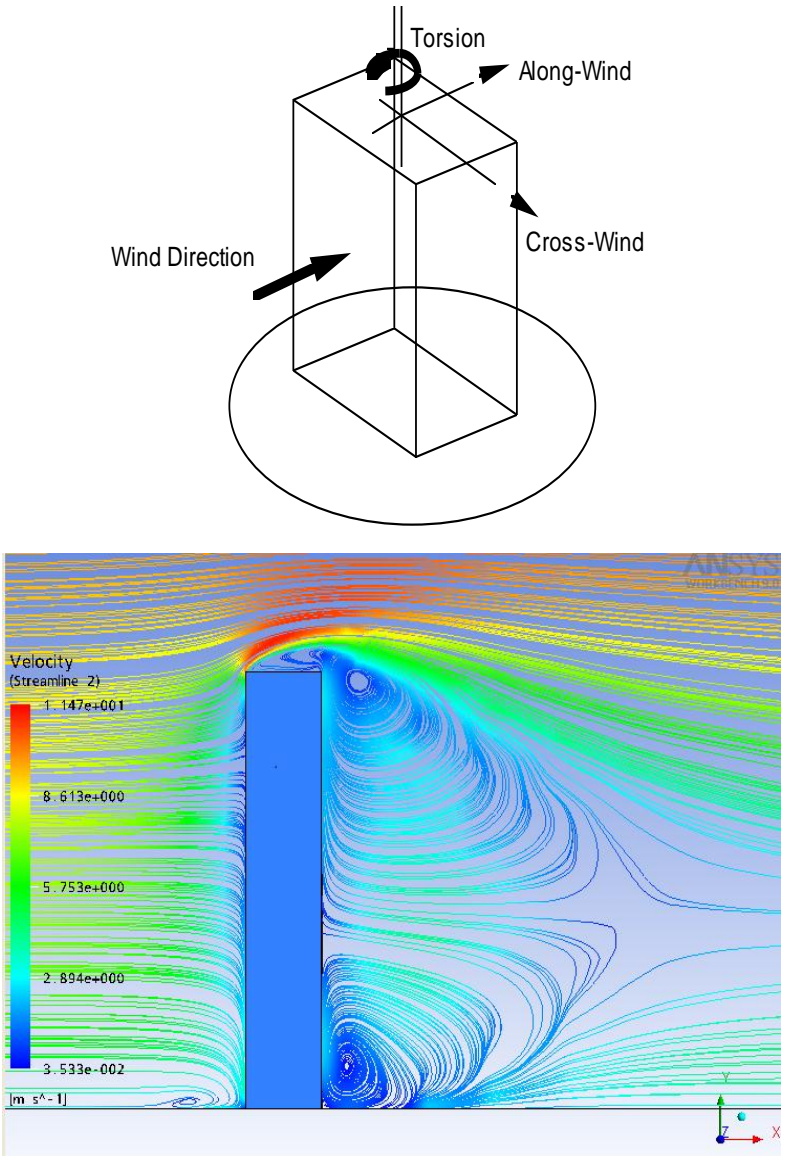

Figure 4. Wind Respose of Tall Buildings

A CFD-based Virtual Wind Tunnel (CFD-VWT) can be used to predict accurately the mean and resultant peak base bending moments in along-wind direction. It can also capture accurately the vortex shedding, which is the primary cause of the crosswind responses in tall buildings. This work is continuing at the University of Melbourne. In the future these methods will be used more often than experimental techniques to predict the wind behaviour around the super tall buildings including pedestrian comfort at the base of the building.

\section{Earthquake Design for Tall Buildings}

The design of tall buildings in seismically active regions varies dramatically from region to region. The performance of a tall building under earthquake loading depends on the configuration of the structural system, the design procedure, the detailing of the structural elements and careful construction.

Traditionally, force-based methods have been used for seismic structural design. Code based methods are not necessarily conservative in some cases [6]. The economic losses resulting from several earthquakes, has prompted the earthquake engineering community to embrace the concept of performancebased earthquake engineering [7].
Although there are many methods available for the seismic analysis of buildings, there is a common acceptance within the design community that the existing methods are not suitable for the analysis of very tall buildings, since most of these methods were derived based on low-to-medium-rise buildings. Moreover, the methods that are available for the seismic design for tall buildings consume a considerable amount of time for the analysis even with the use of sophisticated computers. A simple and versatile method was developed at the University of Melbourne, based on direct displacement-based design for outrigger braced tall buildings, under the supervision of the author, by Herath [8].

Traditional engineering practice is mainly focused on only first translational mode when setting strength requirements and lateral force distributions in earthquake design for buildings. As mentioned earlier, the reason behind this phenomenon was that most of the existing building codes of practice were developed based on the behaviour of low-rise buildings, which are not influenced much by higher mode effects. However the higher mode participation in tall buildings cannot be neglected as there is a significant impact from these mode responses for the overall response of the building. The significant impact on the behaviour of such buildings from higher mode participation including period lengthening was highlighted by Herath [8].

\section{Progressive Collapse}

Several recent building collapses such as the Murrah building in Oklahoma (1995) and the collapse of the World Trade Centre (WTC, 2001) have shown the importance of designing buildings considering the possibility of progressive collapse. Progressive collapse is characterized by the loss of load-carrying capacity of a relatively small portion of the structure due to an abnormal load which can trigger a cascade of failures affecting a major portion of the structure. Lessons learnt from these events were that special attention must be given to the behavior of the structural elements to improve their redundancy, toughness, and ductility under extreme events [9]. The ultimate goal of the protection is to minimize injuries and loss of life and facilitate the evacuation and rescue of survivors. The casualties that will occur to occupants in the immediate vicinity of the explosion or impact may be unavoidable, but by preventing progressive collapse, the remaining occupants may be spared from injury or death.

An accurate advanced analysis procedure has been developed by the Advanced Protective Technologies for Engineering Structures group (APTES) at the University of Melbourne to predict the progressive 
collapse of tall buildings using advanced finite element techniques. This work was funded by the Department of Prime Minister and Cabinet in Australia. An example is given in Figure 5.

In this building, every element and reinforcement details were modeled and the progressive collapse was initiated by removing a column. Many weaknesses were identified in the present design methods which need to be taken into account in developing innovative and effective mitigation technologies for the protection of critical, high rise facilities from extreme events such as shock, blast, impact and earthquakes.
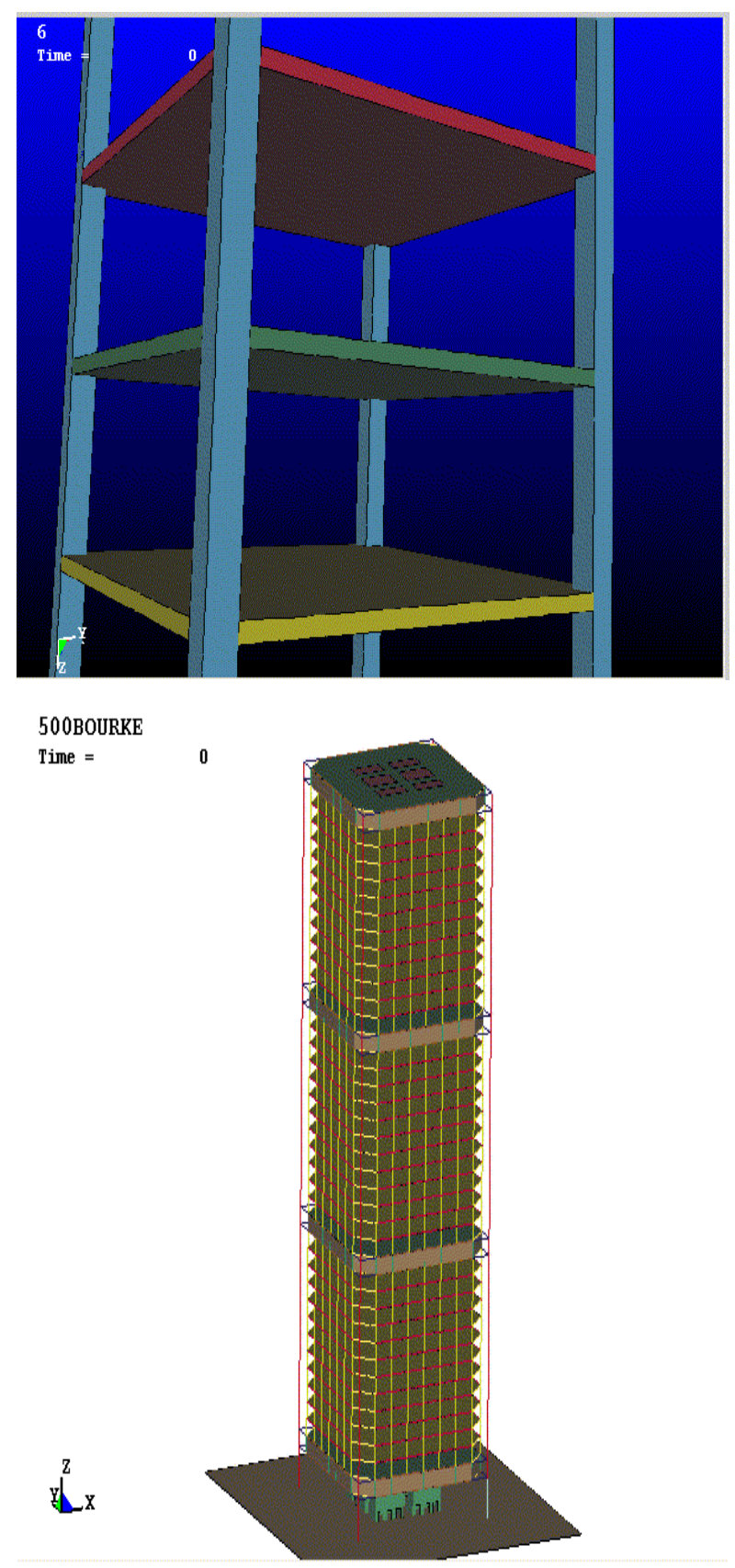

Figure 5. Advanced Numerical Models for Progressive Collapse

\section{Fire Protection}

The fire proofing of structural steel members and other fire protection methods used in tall buildings have been called into question in the aftermath of 9/11 [10]. A large amount of fireproofing was dislodged from the steel members as a result of the initial impact and the explosion of the aircraft. Questions have been raised as to whether the fireproofing should be thickened, and whether there is a requirement to develop new products.

The fire designs carried out now are based on standard fires. Fires originating from jet fuel, such as in the WTC, are hydrocarbon fires, which are different to standard fires. In hydrocarbon fires the temperature increases rapidly (in a few seconds) compared to a standard fire, in which the maximum temperature is reached after some time. Concrete, which is the main construction material for tall buildings, is susceptible to shattering (spalling) under rapid and high intensity heat; for example, following the ignition of hydrocarbon fuel. Even steel members may behave differently under a hydrocarbon fire. The collaborative research project at the University of Melbourne (with Permasteelisa Ltd) will investigate the fire performance of Glass Fiber Reinforced Polymer (GFRP) facades in tall buildings.

As tall buildings continue to be built to meet the need for space in cities, it is essential for planners and builders to pay attention to disasters that have already occurred, to visualize the possibility of these events in the future, and conduct research and development work that mobilizes the support of practicing engineers and scientific personnel, including collaborating with specialists in universities and other research organizations. This will mean that designers will begin to do things differently, and this will enhance the safety of the occupants of tall buildings that are susceptible to extreme loads [10].

\section{Sustainable Design of Tall Buildings}

Evidence indicates that sustainable buildings have lower vacancy rates, higher rents, and increased property values. Sustainable design implies many factors such as energy efficiency, environmental friendliness, adaptability and efficient use of resources.

Environmental issues continue to become increasingly significant and hence the building operational energy efficiency and the energy required for construction and consequently, for the material production, are getting greater importance. The commercial buildings, in general, consumes significant amount of materials in construction and consumes significant amount of energy during operation. Therefore, 
it is essential to determine both embodied energy and operational energy together with the related Green House Gas (GHG) emissions.

A study was conducted at University of Melbourne to quantify and compare the embodied energy, operational energy and green house gas emission of concrete and steel framed options, which are commonly used in commercial buildings. A typical high rise office building in Melbourne was chosen for this exercise (Figure 6). The studied building is a 50 storey with a flat roof and the total net-lettable area (NLA) of 75,570 square meters. The embodied energy contribution of the substructure, the super structure with the structural elements namely foundation, beams, columns roof, facades and stairs were investigated. The results are summarised in Table 1.

The foundation contributed to the highest embodied energy of $24.5 \%$ in case of the concrete building, whereas for the steel building, beams represented the highest embodied energy of $36.9 \%$ of the total.

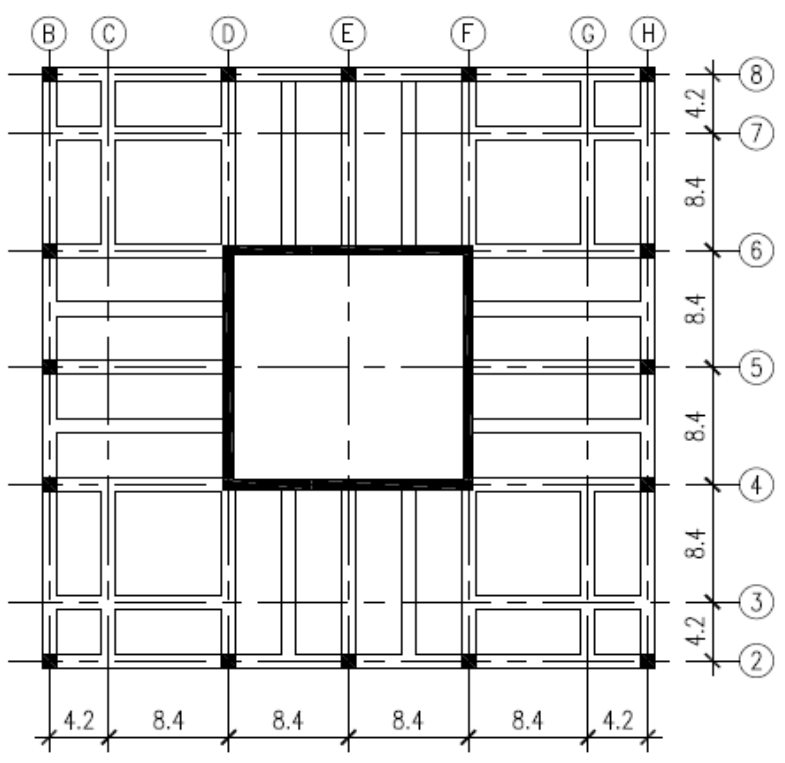

Figure 6. Plan View of the Building
The results also showed for a 50 year period the operational GHG emission was significantly higher that the initial embodied GHG emission. Further, it was shown that the steel framed building has $68 \%$ more embodied green house gas emission as compared to the concrete framed building. It is clearly evident that the material choice in the construction of building has an important effect on the amount of GHG emission. The study has its limitation when it comes to the embodied energy calculation via recycling of both concrete and steel. It requires extensive and reliable data, and is beyond the scope of this paper.

There are many building evaluation tools that focus on different areas of sustainable development and are designed for different types of projects. Examples are BREEAM, LEED, GREEN STAR and Home Grown (developed to be suitable for local conditions) rating tools such as Malaysian GBI Index, Singapore's Green Mark system, Indonesian Greenship and Sri Lanka's Green Rating System for Built Environment (GRSBE).

The categories available in these systems can be grouped in broad form as below:

- Building energy consumption

- Water efficiency

- Indoor and outdoor environmental quality \& emissions

- Material \& resources

- Site development strategies

\section{Concluding Remarks}

Both safety and sustainability have to be considered in designing tall buildings. Still these buildings are designed and constructed using conventional techniques. However it is very important to incorporate new high-performance materials such as composites (fibre reinforced polymers), high-performance concretes with nanomaterials, very high-strength steels, bioinspired materials etc. in the future to improve the safety and sustainability. Advanced computational techniques can be used to quantify and further optimize the systems.

Table 1. Embodied Energy (EE) and Embodied GHG Emission (NLA= $75570 \mathrm{~m}^{2}$ )

\begin{tabular}{|c|c|c|c|c|c|c|c|c|}
\hline \multirow{2}{*}{ Element } & \multicolumn{2}{|c|}{ Total Volume $\left(\mathrm{m}^{3}\right)$} & \multicolumn{2}{|c|}{ Total Weight (t) } & \multicolumn{2}{|c|}{ EE (GJ) } & \multicolumn{2}{|c|}{ EGHG (t CO } \\
\hline & $\mathrm{C}$ & $\mathrm{S}$ & $\mathrm{C}$ & $\mathrm{S}$ & $\mathrm{C}$ & $\mathrm{S}$ & $\mathrm{C}$ & $\mathrm{S}$ \\
\hline Foundation & 9623 & 9623 & 23619 & 23619 & 124164 & 124164 & 8421 & 8421 \\
\hline Beam & 9023 & 474 & 22245 & 3722 & 117314 & 318118 & 8054 & 21217 \\
\hline Column & 1857 & 265 & 4660 & 2083 & 36311 & 178014 & 2449 & 11873 \\
\hline Slabs & 9351 & 10187 & 22850 & 24893 & 96672 & 105316 & 6687 & 7285 \\
\hline Shear Walls & 8884 & 8884 & 21805 & 21805 & 103671 & 103671 & 7141 & 7141 \\
\hline Staircase & 165 & 165 & 404 & 404 & 1922 & 1922 & 132 & 132 \\
\hline Roof slab & 414 & 252 & 1016 & 667 & 4761 & 8870 & 328 & 598 \\
\hline Façade & 510 & 510 & 1226 & 1226 & 22578 & 22578 & 2229 & 2229 \\
\hline Total & 39827 & 30360 & 97825 & 78419 & 507392 & 862653 & 35441 & 58896 \\
\hline
\end{tabular}




\section{References}

1. CTBUH, Recommendations for the Seismic Design of High-rise Buildings, The Council on Tall Buildings and Urban Habitat (CTBUH), 2008.

2. Mendis, P., Design of High-strength Concrete Members: State-of-the-art, Engineers Australia Pty Limited, 2001.

3. CTBUH, Case Study-Shanghai Tower, The Council on Tall Buildings and Urban Habitat, 2010.

4. Mendis, P., Ngo, T., Haritos, N., Hira, A., Samali, B., and Cheung, J., Wind Loading on Tall Buildings, Electronic Journal of Structural Engineering (Special Issue: Loading on Structures), 2007, pp. 41-54.

5. Cuong, N.K., A Study of Aerodynamic Wind Loads on Tall Buildings using Wind Tunnel Tests and Numerical Simulations, PhD Thesis, The University of Melbourne, Melbourne, 2009.

6. Pudjisuryadi, P. and Lumantarna, B., Evaluation of Column's Flexural Strength of Special Moment
Resisting Frame in Accordance to the Indonesian Concrete and Earthquake Codes, Proceedings of the International Conference on Earthquake Engineering and Disaster Mitigation, 2008, pp. 591-599.

7. Kusuma, G., Mendis, P. and Ngo, T., Use of Performance and Energy-based Methods for the Evaluation of Concrete Structures Subjected to the 2006 Yogyakarta Earthquake, Proceedings of the 8th Pacific Conference on Earthquake Engineering, 2007, paper 312.

8. Herath, N., Behaviour of Outrigger Braced Tall Buildings Subjected to Earthquake Loads, $\mathrm{PhD}$ Thesis, The University of Melbourne, Melbourne, 2011.

9. Ngo, T., Mendis, P., and Kusuma, G., Vulnerability Assessment of Concrete Tall Buildings Subjected to Extreme Loading Conditions. Proceedings of the CIB-CTBUH International Conference on Tall Buildings, Malaysia, 2003.

10. Mendis, P. and Ngo, T., Five Years on Changes in Tall Building Design?, Electronic Journal of Structural Engineering, 6 (Special Article), 2006. 